\title{
Smart Attendance Application Using Android and PHP
}

\author{
Sanya Patel ${ }^{1}$, Aliya Sayyed ${ }^{2}$, P.P Bastawade ${ }^{3}$ \\ All India Shri Shivaji Memorial Society’s Polytechnic Pune, India 1, 2,3
}

\begin{abstract}
Taking attendance in a class can often be a time consuming and a manual process, which is prone to human errors and incorrect recorded data. Also, maintaining the data for every student can be a tedious job since it involves some sort of manual efforts. These day's inventions of smart phones and tablets which are very handy to use, this process can be made completely automated and error free by using the right technologies. In this project we have created an android application, server and a database that is used for taking and storing attendance which is easy to use and time saving. Once the attendance is taken, the attendance is stored at the database and the teacher can view the data accordingly. The teacher can even send e-mail to the student's parent manually.
\end{abstract}

Keywords: Notification, XAMPP, Android studio.

\section{INTRODUCTON}

With the massive of mobile in computing era, smart meet the needs of many different environments by using phones became popular devices are getting grip. The extensions and modules. Most word Press hosting feature of the application for these devices relies on providers use Apache as their web server software. remote servers on the cloud, and Google Cloud Messaging However, Word Press can run on other web server $(\mathrm{GCM})$ is a popular service as a client/server software as well. Apache supports a variety of features, communication solution for Android. [1]Android is an many implemented as compiled modules which extend the open source operating system, Devices which it runs the core functionality. These can range from server-side Android application work on any mobile that support programming language support to authentication schemes. android O.S with different screen size. [2] .This era is very Some common language interfaces support PHP.XAMPP great and exiting for mobile developers.PHP is the most is a free and open source cross-platform web server commonly used as a server-side scripting language. To solution stack package developed by Apache friends, make PHP work as a server-side scripting language, all consisting mainly of the Apache HTTP server, Maria DB you needis a PHP parser, a Web server, and from the database, and interpreters for scripts written in the PHP command line. Developing with Eclipse is the preferred and Perl programming languages. XAMPP stands for method because it can directly invoke the tools that needed cross-platform(X), Apache (A), Maria DB (M), PHP (P), while developing applications. [3]. Android is a software and Perl (P). It is a simple, lightweight Apache distribution stack for mobile devices that includes an operating system, that makes it extremely easy for developers to create a middleware and key applications. The Android SDK local web server for testing and deployment process. provides the tools and APIs necessary to begin developing Everything needed to set up a web server- server applications on the Android platform using the Java application, database, and scripting language (PHP) is programming language. Android based on Linux version included in an extractable file. XAMPP is also cross2.6. The system services such as security, memory platform which means it works equally well on Linux, management, process management are controlled by Mac and Windows.

Linux. [4.6].The Apache HTTP Server, normally called Apache is the world's most used web server software. Originally based on the NCSA HTTP server, development of Apache began in early 1995 after work on the NCSA code stalled. Apache played a key role in the initial growth of the World Wide Web, quickly overtaking NCSA HTTP as the dominant HTTP server, and has remained most popular since April 1996. In 2009, it became the first web server software to serve more than 100 million websites. Apache is the most widely used web server software. Developed and maintained by Apache Software foundation, Apache is open source software available for free. It runs on $67 \%$ of all web servers in the world. It is fast, reliable, and secure. It can be highly customized to

\section{Features of Android studio-}

- Gradle based build support.

- Android specific refactoring and quick fixes.

- Lint tools to catch performance, usability, version compatibility and other problems.

- Pro-guard integration and app-signing capabilities.

- Template based wizards to create common android designs and components.

- A rich layout editor that allows users to drag and drop UI components, option to preview layout on multiple screen configurations.

- Support for building android applications. 
- Built in support for Google cloud platform, enabling integration with Google cloud Messaging and application engine.

\section{Features of XAMPP server:}

- XAMPP provides support for creating and manipulating databases in Maria DB and SQLite among others.

- It is possible to treat a local host like a remote host by connecting using an FTP client

\section{EXISTING SYSTEM}

The existing system is a manual entry for the students. Here the attendance will be carried out in the hand written registers. It will be a tedious job to maintain the record for the user. The human effort is more here. The retrieval of the information is not as easy as the records are maintained in the hand written registers. This application requires correct feed on input into the respective field. Suppose the wrong inputs are entered, the application resist to work and if the register is lost the data cannot be retrieved back. So the user finds it difficult to use.

\section{PROPOSED SYSTEM}

To overcome the drawbacks of the existing system, the proposed system has been evolved. This project aims to reduce the paper work and saving time to generate accurate results from the student's attendance. The system provides with the best user interface. The efficient reports can be generated by using this system. This system provides customized views to see attendance records of students and further this record can be exported in spreadsheet format. This application will help the Teacher/Admin to view the attendance yearly/ monthly date wise etc, according to users need. This application keeps the track on the student's attendance and those students who have less attendance an e-mail will be sent to the student's parent mobile number. The e-mail will go automatically on selected date or day. In this application the teacher can easily add a subject. He/she can add as many students as he/ she wants per subject. Each subject will contain all attendance history of all students as well as for a specific student showing all his past records. The Admin/teacher can delete student as well as student attendance history. This android application is connected to a server computer via networking device (Router).

\section{BASIC IDEA}

Smart attendance is an application for teachers that will help to take and manage attendance of their classes. This app can be used by any teacher no matter you are a primary school teacher, college professor or professional lecturers. In this android application admin can register $n$ numbers of teachers from the database, the teacher can then log-in through the android application and after following few simple steps teacher can take the attendance of the students which gets stored in the data base automatically. The teacher can also view the attendance from the android application. The teacher can also log-in the database through the teacher's panel to view the student information and attendance. The teacher can also e-mail the student's attendance to their parents. The overall architecture of the Application is shown in Fig 1. Which consist of two main parts, Android application for registering and reception of notification, and a server side for the instructor to select his courses, section, student or students to send E-mail.

The proposed system is divided into two parts the first is server part and theother is android application. The flow of system goes in such a way that when the user log-in from the database the first thing seen in the database server is the panel. There are two different panel one is admin panel other is teacher panel.

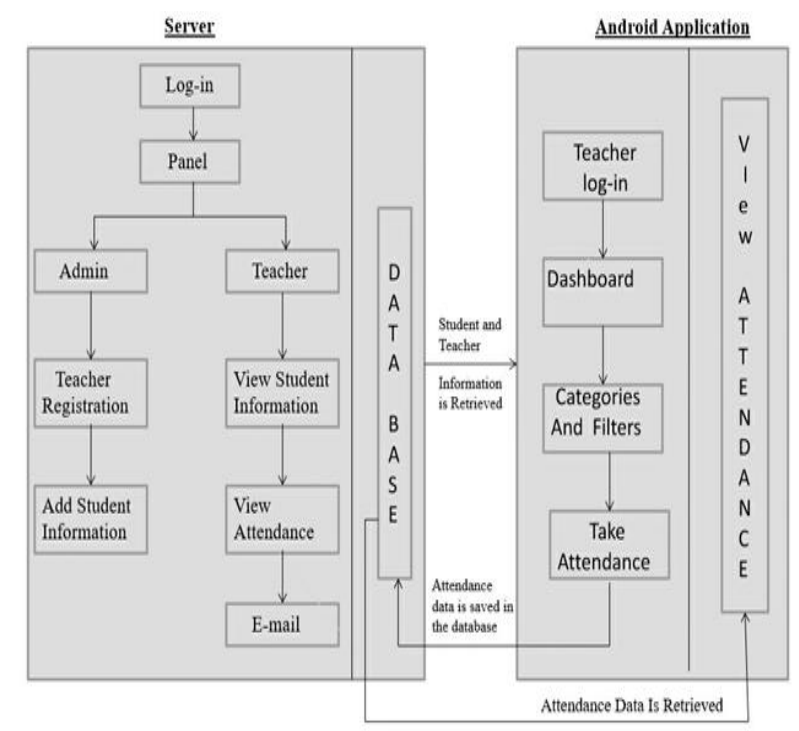

Fig 1 Architecture of System

When the admin log-in from the log-in page the admin can register the teacher and fill the teacher information, the admin can also add student information manually and accordingly. When the teacher log-in from the teacher panel he/she can view student information, view attendance and can send e-mail to the parent from database. The teacher can even log-in from an android application and the teacher can take attendance in few clicks going through some categories and filters and then the attendance taken will be stored in the database. Teacher can view the attendance in android application. The attendance saved at the database will be retrieved using some web services. This application has a nice user interface which is user friendly and can be used by any teacher in any institute.

Here, the teacher can log-in with the username and password which was set from the database. 


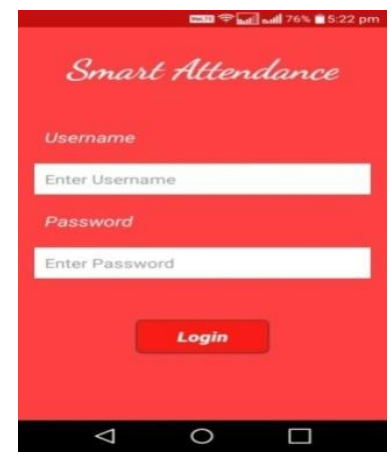

Fig 2.Teacher's log-in

This is the dashboard of the application. It is very user friendly and has good user interface.

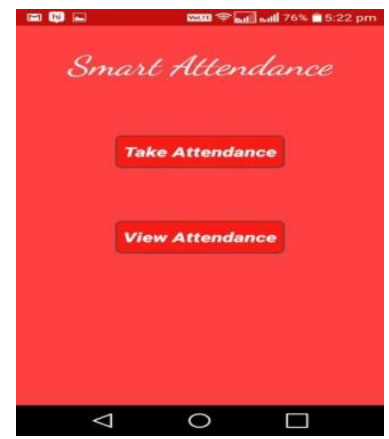

Fig 3. Dashboard

This is department filter where the teacher can select the appropriate department in which he/she teaches.

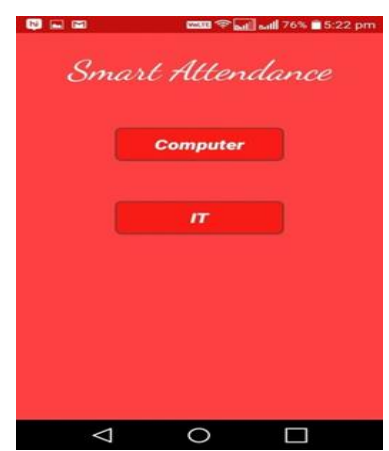

Fig 4. Department Filter

This is shift register where the teacher can select the appropriate shift in which he/she teaches.

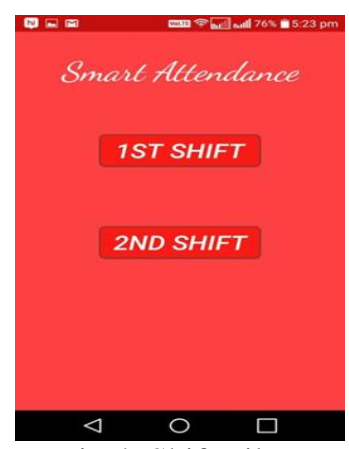

Fig 4. Shift Filter
This is the year filter in which the teacher can select the year in which he/she teaches.

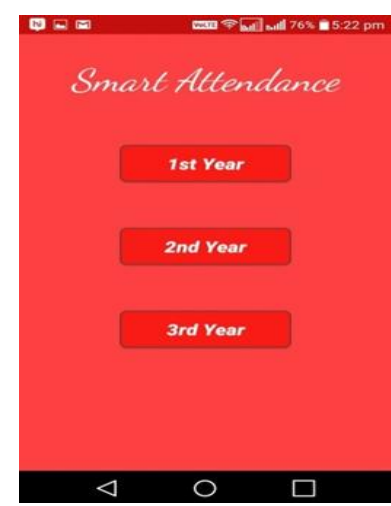

Fig 5. Year Filter

The taking attendance filter is in which the teacher takes the attendance of the students of the class.

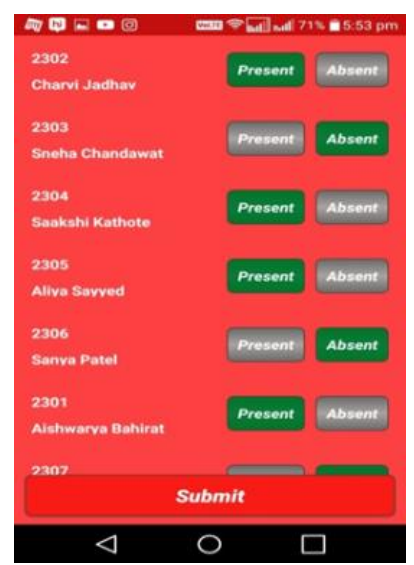

Fig 6. Taking Attendance

This filter is used to view the attendance. The teacher can put the start date, end date and student's roll no and press go. The attendance will be viewed.

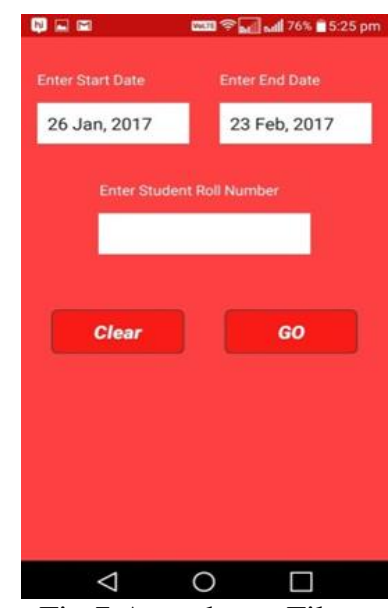

Fig 7.Attendance Filter

When the teacher wants to view the attendance the attendance will be viewed in this way. 


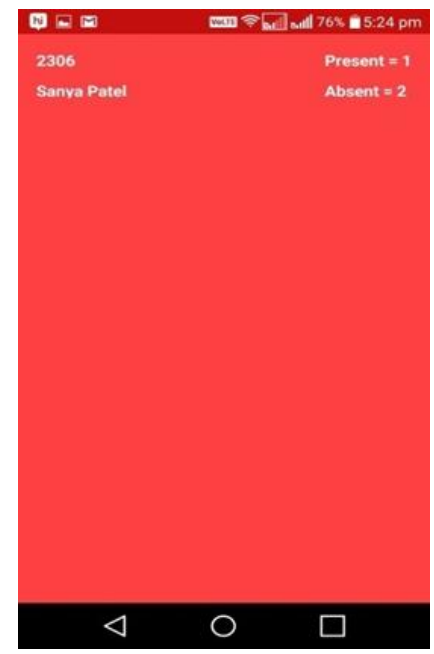

Fig 8.Viewing Attendance

\section{B. Database}

The Database has been created in PHP my admin, in SQL format. The Database plays an important role in this project as it is responsible for registering teachers i.e. assigning the usernames and password, and entering student information i.e. their personal information. The Database is also responsible for sending E-mails to the student's parents regarding their attendance.

\section{- Teacher Log-in}

The Database has two log-in:
1
Admin log-in
2) Teacher's log-in

Every teacher can log-in into the Database with their respective username and password. The teacher can then view student's attendance and their information. The teacher can also send emails to the student's parents regarding their attendance.

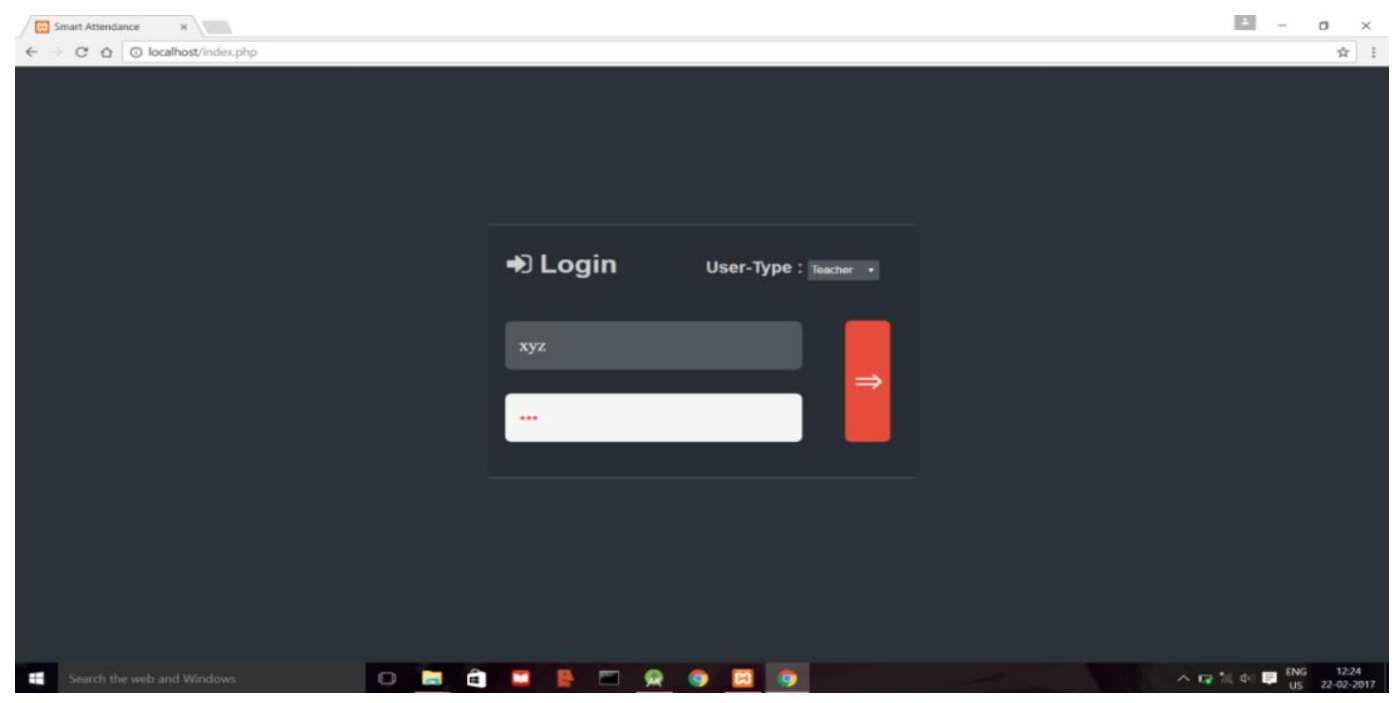

\section{- Teacher's Panel Student Section}

information a search bar is giving to search the student After logging in through the teacher's panel the teacher such as student's enrollment no, roll no, parents name, enter the dashboard where the teacher can see student's contact no and parents e-mail address.

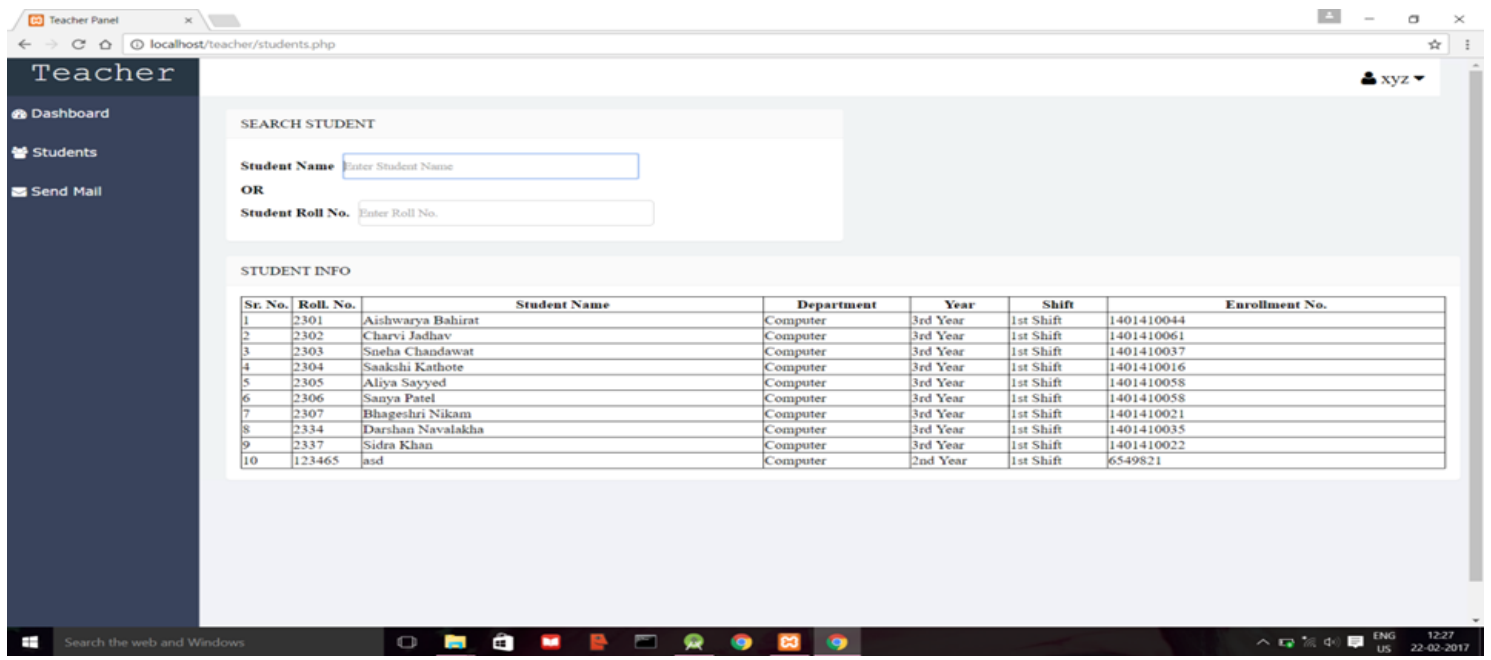


- View of Attendance

On the left side of the dashboard there is a button to view the student's attendance the teacher has to enter to and from date and has to select year, department and subject as per their requirement. After all the filters are applied the teacher gets a view of the student's attendance like the image shown below.

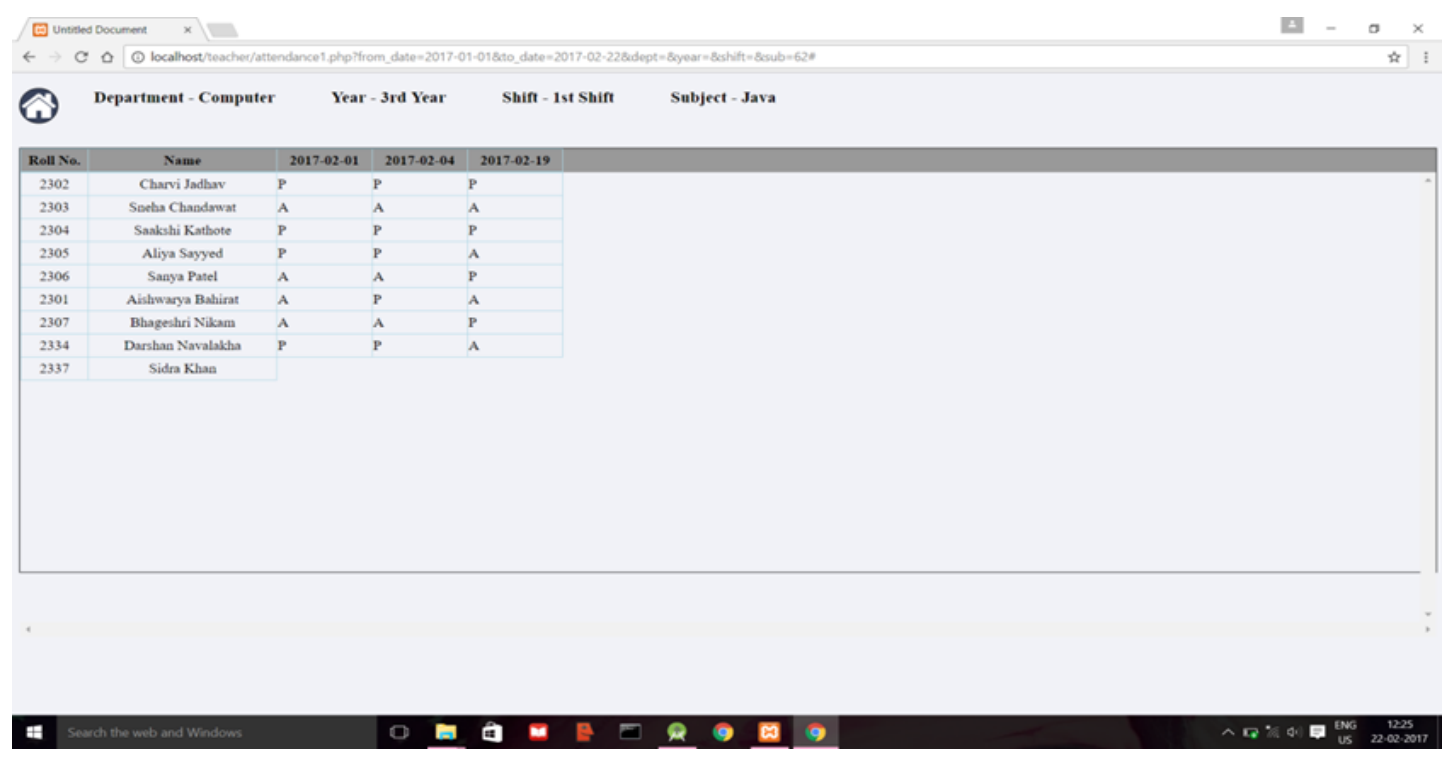

\section{- E-mail Section}

A teacher can send an email to either a single individuals parents or to the entire class's parents. The teacher has to select the year, department and subject and select all if she wants to send an email to the entire class's parents or select a particular student whom she wishes to send a mail.

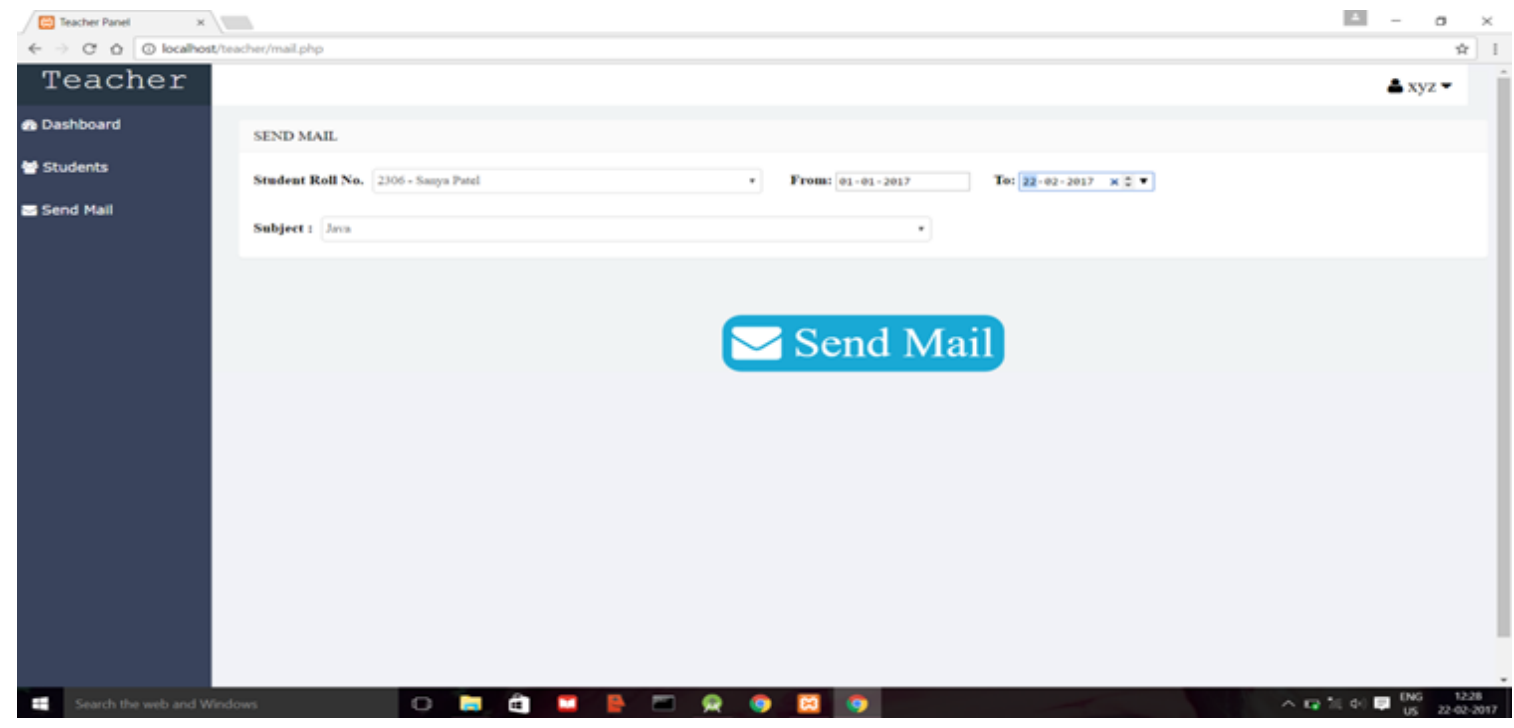

\section{FEATURES OF PROPOSED SYSTEM}

- Less use of paper and stationary.

- Saves time required to take attendance.

- Storage of attendance is easier.

- Generation of attendance report is easier.

- It is trouble-free to use.

- It is relatively fast approach to enter attendance.

- It is highly reliable.

- Best user interface

- Saves time.
- Resists student from bunking classes through e-mail sending features to parent.

- Generates reports of any student in few clicks.

\section{CONCLUSION}

Registering attendance during a class can be very time consuming process, which requires manual steps and is error prone. This application solves all the downfalls of registering attendance manually. It allows professor to take attendance of the students accordingly. The teacher can view the database from the android application as well 
as PHP server, which not only saves time but is also error free. Additionally, professor has the luxury to look at attendance record of students whenever he wants. Just a few clicks away! Professor can also query and look up to those students whose attendance did not meet minimum criteria and send e-mail to the parent. Smart attendance is an application that helps teachers to take and manage attendance of their classes effectively and efficiently. This application reduces manual effort of entering the attendance in the system.

\section{FUTURE WORKS}

The project has a very vast scope in future. The project can be implemented on intranet in future. Project can be updated in near future as and when requirement for the same arises, as it is very flexible in terms of expansion. With the proposed software of database space manager ready and fully functional the client is now able to manage and hence run the entire work in a much better, accurate and error free manner. In future a barcode can be given to teacher as well as student and the developer can also develop a barcode scanner in the mobile phone which will reduce time wastage. The developer can also use biometrics for teachers and admin to log-in. the application like this will be very helpful for future generation.

\section{ACKNOWLEDGEMENT}

This work is completed under the guidance of Prof. Prajakta Bastawade We express our gratitude towards them for their continuous support on this research. We would also like to thank the reviewers for their suggestions to improve this paper.

\section{REFERENCES}

[1] avuzSelimYilmazBahadir Ismail Aydin Murat Demirbas, 2014 "Google Cloud Messaging (GCM): An Evaluation" GlobecomSymposium on Selected Areas in Communications: GC14 SAC Internet of Things, (C2014 IEEE, pp2847-2852

[2] http://developer.android.com/google/gcm/index.htm

[3] GarimaPandey, DikshaDani, 2014" Adroid Mobile Application Build on Eclipse", International Journal of Scientific and ResearchPublications, Volume 4, Issue 2, February 2014 , ISSN 2250-3153, www.ijsrp.org.

[4] SuhasHolla, Mahima M Katti, 2012 "Android Based Mobile Application Development And Its Security", International Journal of Computer Trendsand Technology- volume3Issue3- 2012,PP 486490,ISSN:2231-2803

[5] Andy Harris, 2009. PHP 6/ MySQL Programming for the Absolute Beginner, 1st Edition, ISBN-10: 1598637983 | ISBN-13: 9781598637984, 2009.

[6] Li Ma, Lei Gu, and Jin Wang, 2014. "Research and Development of Mobile Application for Android Platform", International Journal of Multimedia and Ubiquitous Engineering Vol.9, No.4 (2014), pp.187-198, ISSN: 1975-0080 IJMUE Copyright @ 2014 SERSC, http://dx.doi.org/10.14257/ijmue.2014.9.4.20.

[7] Wei- Meng Lee, 2012. Beginning Android 4 Application Development, ISBN: 978-1-118-19954-1, March 2012. 